\title{
Information Warfare: Fact or Fiction?
}

\section{M.J.Warren $\uparrow$ and W.Hutchinson†}

† School of Computing and Mathematics

Deakin University,

Geelong, Victoria,

Australia.

Email contact: mwarren@deakin.edu.au.

\author{
$\ddagger$ School of MIS \\ Edith Cowan University, \\ Perth, Western Australia, \\ Australia
}

Key words: Information Warfare, Computer Security, National Information Infrastructure.

Abstract: $\quad$ The aim of the paper to explore what Information Warfare is and the impact that it could have upon a country. The paper will then discuss the impact that information warfare could have upon Australia. This assessment will take the form of evaluating two national studies undertaken within Australia into Information Warfare and look at the risks that could effect E-commerce. The paper will also describe the steps that some countries are taking to protect themselves against the threat of Information Warfare.

\section{INTRODUCTION}

During the last ten years there has been a growth of Information Systems and related Internet technology within the developed world. In recent years the Internet has grown from a solely military or academic network to one that can be used by business or individuals. There has been a rise in computer misuse at a global level and also the development of new policies and strategies to describe organised computer security attacks against the information society - these strategies are described as Information Warfare (IW). The aim of the paper is to discuss what Information Warfare is and the likely impact that it will have upon countries and business organisations.

The original version of this chapter was revised: The copyright line was incorrect. This has been corrected. The Erratum to this chapter is available at DOI: 10.1007/978-0-387-35515-3_53 


\section{WHAT IS INFORMATION WARFARE?}

Primarily, Information Warfare is concerned with damaging a country's National Information Infrastructure (NII) [Schwartau, 1994]. What is the National Information Infrastructure? For the purposes of this paper, the NII is defined as the physical and virtual backbone of an information society and includes, at a minimum, all of the following [Cobb, 1998]:

$\xi$ government networks-executive and agencies;

$\xi$ banking and financial networks-stock exchanges, electronic money transfers;

$\xi \quad$ public utility networks-telecommunication systems;

$\xi$ emergency services networks (including medical, police, fire, and rescue);

$\xi$ mass media dissemination systems-satellite, TV, radio, and Internet;

$\xi$ private corporate and institutional networks, and

$\xi$ educational and research networks.

Therefore Information Warfare at a theoretical level is concerned with protecting a nations information systems. Importantly IW has also been associated with the so called 'Revolution in Military Affairs' (RMA). In some respects IW is a sub-set of the RMA, which is also concerned with the military application of new technologies to the 'battlespace' [Cobb, 1998], such as stealth, precision guided munitions, and advanced surveillance capabilities. The vulnerabilities of the commercial aspect of the NII is now a major source of concern and these new risks will be looked at in the latter part of the paper.

\section{AUSTRALIAN CASE STUDIES}

Within Australia two public major studies into the impact of Information Warfare have been undertaken. The studies were undertaken by Foreign Affairs, Defence and Trade Group [Cobb, 1998] and the Attorney General [Attorney-General's Department, 1998].

\subsection{Foreign Affairs, Defence and Trade (FADT) Group Study}

The initial study was undertaken by the Australian National University [Cobb, 1997] and then the FADT Group [Cobb, 1998]. The aim of the study was to determine the risks that the Australian NII faced. With respect to 
information based vulnerabilities, the study split vital information-dependent systems into three distinct groupings [Cobb, 1998]:

Core state functions: executive government, and essential agencies such as defence, intelligence, foreign affairs and trade, finance, social security, national and state emergency services.

Core utility functions: power grids, telecommunications, petrol refineries, gas and oil storage and transportation systems, transportation and traffic systems (air traffic control, guidance systems, meteorological support), and water supply.

Core commercial functions: banking and financial services, mass media, business systems and communication networks.

The risk assessment of the studies suggests a hierarchy of threats facing Australia's critical infrastructures. In descending order of probability and consequence of seriously damaging Australia's national security, wealth, and international image, they are:

$\xi \quad \mathrm{Y} 2 \mathrm{~K}$ incompatibility;

$\xi$ information-terrorism at the Sydney 2000 Olympics;

$\xi$ major crime activity;

$\xi$ natural disaster;

$\xi$ state and non-state terrorism (excluding the Olympics);

$\xi$ information warfare-civilian systems, and

$\xi$ Information Warfare-military systems.

Of these would be risks, the $\mathrm{Y} 2 \mathrm{~K}$ incompatibility problems did not develop and hopefully problems in connection with the Olympics will also not develop. This therefore means that major crime activity is considered the main information warfare risk against Australia. Criminals and organised crime groups have been quick to seize the opportunity afforded by new communications technologies and their rapid spread throughout society. An Australian expert claimed recently that 'big crime cartels are at least two years ahead of the business world in their take-up of sophisticated technology' [McIntosh, 1997]. The study highlighted four main proposals that could be easily adopted with minimal expense:

$\xi$ encryption already gives a level of security to a number of critical operating systems and should be more widely used;

$\xi$ human rather than technological solutions play an important part in enhancing information security;

$\xi$ corporate plans must be revised to include information systemrelated contingencies;

$\xi$ a new national monitoring agency to be set-up to protect Australia. 


\subsection{Attorney General Study}

In February 1997 Australian Defence Signals Directorate (DSD) published a confidential report Australia's National Information Infrastructure: Threats and Vulnerabilities [Attorney-General's Department, 1998] The principal recommendation was the establishment of a formal structure involving both Government and the private sector to co-ordinate and implement national policy for protection of the NII. Supplementary recommendations covered collection and assessment of information, raising levels of awareness and protection, and the establishment of a national computer emergency response team and a vulnerability analysis team. The Attorney General's report was an extension of the DSD 1997 report to develop a more formal national approach to information warfare and its impact upon Australia. The study suggested the following steps [AttorneyGeneral's Department, 1998]:

\section{Formal Structure of Protection}

The need to develop a formal structure for protection of the Australian national information infrastructure. This will included an annual budget of AU $\$ 1.7 \mathrm{~m}$ per annum in salaries and administrative costs. The formal structure must be agreed by both the Australian government interdepartmental committee and the Industry Forum (industrial representative organisation).

\section{Co-ordination of National Infrastructure}

Co-ordination of activities aimed at addressing the protection of the national infrastructure including the national information infrastructure.

\section{Training Accreditation}

Development of a scheme for the accreditation of training courses covering topics relevant to NII protection

\section{Integration of Crisis Management Arrangements}

Develop crisis management arrangements for information warfare attacks. Attacks against the NII will, in many cases, include an element of political motivation. The more realistic scenario in the long term is that there are likely to be elements of information attacks in general politically motivated attacks. The crisis management arrangements for both will be similar. The Commonwealth is already developing extensive crisis management arrangements for the Sydney Olympics. These arrangements will need to include measures to respond to information attacks. 


\section{Research and Development}

One of the longer term strategies is to ensure adequate technical capabilities to address current and future threats. This can be achieved through strategic targeting of research and development. While funding of research and development into information security would not be a responsibility of the proposed structure, it could play a role in supporting applications for funding from other sources. Such funding could be facilitated where projects are identified as having a significant national interest component.

\section{International Co-operation}

Australia already participates in a number of international organisations whose activities touch on the national information infrastructure or elements of its protection. Indeed one, FIRST (Forum of Incident Response and Security Teams), is dedicated to particular aspects of NII protection. There is not, however, an inter-governmental forum which addresses the broad issues at a national government level

The recommendations from this study are being implemented by the Australian federal government.

\section{A POSSIBLE WEAK LINK IN THE NII}

E-commerce sites represent easy targets for attackers. Security is usually not as tight as in secured military systems, and these systems tend to be always on-line via the Internet. Any damage to these systems creates publicity for the attackers and losses to the businesses concerned (either through physical damage, credibility, or financial loss). Many organisations do not consider the security risks when developing on-line services. Ecommerce is forming an important part of the business aspect of the NII, but is not considered in the same way as other aspects of the NII. The most common attack methods currently available include:

\subsection{Password Sniffing/Cracking Software}

This is one of the simplest and most common method attacks, using software packages such as Brute (PC based), Passfinder (Mac based), Crack V4.1 (Unix based). These packages run in a number of ways, e.g. accessing a system via a File Transfer Protocol (FTP) port and trying to determine password files. Another method is to use software that systematically uses a combination of passwords until one is successful. There are now even commercial companies that offer a password cracking service. An attacker 
might use this software or services in order to gain passwords for further usage or to gain access to systems or data. These type of attacks could damage an organisations E-commerce operation in a number of ways. For example, unauthorised access could allow the attacker to delete, or change data relating to orders and also copy data for future use.

\subsection{Spoofing Attacks}

IP (Internet Protocol) Spoofing was first associated with the hacker Kevin Mitnick [Littman, 1997] and his attacks on networks. It works by forging the 'From' address so that the message appears to have originated from somewhere other than its actual source. Normally, the false address is that of a site which is trusted by the receiving host so that the packet will be accepted and acted upon, in some cases allowing an intruder to penetrate right through a firewall [Denning, 1999]. Another type of spoofing is known as Web spoofing. This is where an attacker sets up a fake web site to lure users in hopes of stealing their credit card numbers or other information. One attacker set up a site called MICROSOFT.com, using the number zero in place of the letter ' $O$ ', which many users might type by mistake. Users might find themselves in a situation that they do not notice they are using a bogus web-site and give their credit card details. A attacker may use these techniques in a number of ways: cracking passwords, or setting up false web-sites with the intent to defraud. Thus raising funds or creating misinformation e.g. pretending the web-site is an official site. The disruption that these attacks would be different to other forms of attack. Since the user using such a site would think they are using an official site they would disclose information relating to their password, customer number, order details, credit cards details, etc. This information could be used later to access the official on-line service and masquerade as a customer and make false orders or they could use the credit card details in other fraudulent activities.

\subsection{Denial of Service Attacks}

A denial-of-service attack results when access to a computer or network resource is intentionally blocked or degraded as a result of malicious action taken by another user. These attacks do not necessarily damage data directly, or permanently (although they could), but they intentionally compromise the availability of the resources [Howard, 1997]. These types of attacks tend to affect the availability of computer systems for legitimate usage. These forms of attacks can include e-mail bomb attacks, systemically sending thousands of emails to a particular computer system email server until that server 
crashes. The software required to carry out denial of service attacks is widely available on the Internet. Another commonly used denial of service attack is the Ping O'Death ('Ping' messages are used to determine the whether another machine on a network is active). The Ping O'Death can crash or reboot a computer by sending a 'ping' message of greater than 65,536 bytes

the default size is 64 bytes. Router updates have nearly eliminated these problems [Mulschlegel, 1997]. Hackers with a low level of expertise would commonly carry out these sorts of attacks. The reason for this is that these attacks require very little technical skill, and the software is freely available on the Internet. Denial of service attacks could be very effective against an Internet based company, since they rely on on-line connectivity. These types of attacks would be very effective in disrupting the on-line mechanisms used by E-commerce applications. The impact of the attacks would be two fold: to cause the system to crash which would mean that businesses cannot access the online service or to send many false email messages to an organisation so that it would take hours to delete and determine which messages were authentic.

\subsection{Direct Attack}

A direct attack would take the form of hacking into a computer system and rewriting or stealing information. This would have a great impact on organisations offering on-line services, since these on-line services could be damaged, modified or destroyed. Another problem is that if the organisation were not able to determine where the security risk lies, the direct attacks would be re-occurring. The impact of these attacks would be to publicise the hackers and destroy the creditability of the organisation offering the on-line services, especially to current and future customers. Hackers have attacked large music companies on-line sites in order to get their message to the general public (as shown by Figure 1) and disrupt the on-line services offered by the record company. Another method of hacking is more concerned with attacking computers files and destroying, modifying or extracting data. These types of hacking attacks may be less apparent to organisations, as they may not realise they have been a victim. Hackers would use direct hacking as an extensive part of their 'attack strategy' against E-commerce. By hacking web-sites they will gain a global audience for their actions and they will also be able to discredit the security of the companies using the on-line services. These types of attacks could damage an organisation's E-commerce functionality in a number of ways. Customers would not be able to access the on-line system until it is restored. However, the biggest impact is the adverse publicity caused for the organisation targeted. It could also affect existing customer confidence in the system and 
reduce the number of future prospective customers. Research within Australia has shown that the main concern that users have about Ecommerce applications is security [DIST, 1998]. This means that direct attacks on E-commerce systems would cause some initial damage but more much importantly could destroy customer confidence in such systems. This could have a dramatic effect upon a countries E-commerce trade sector and could result in significant financial losses.

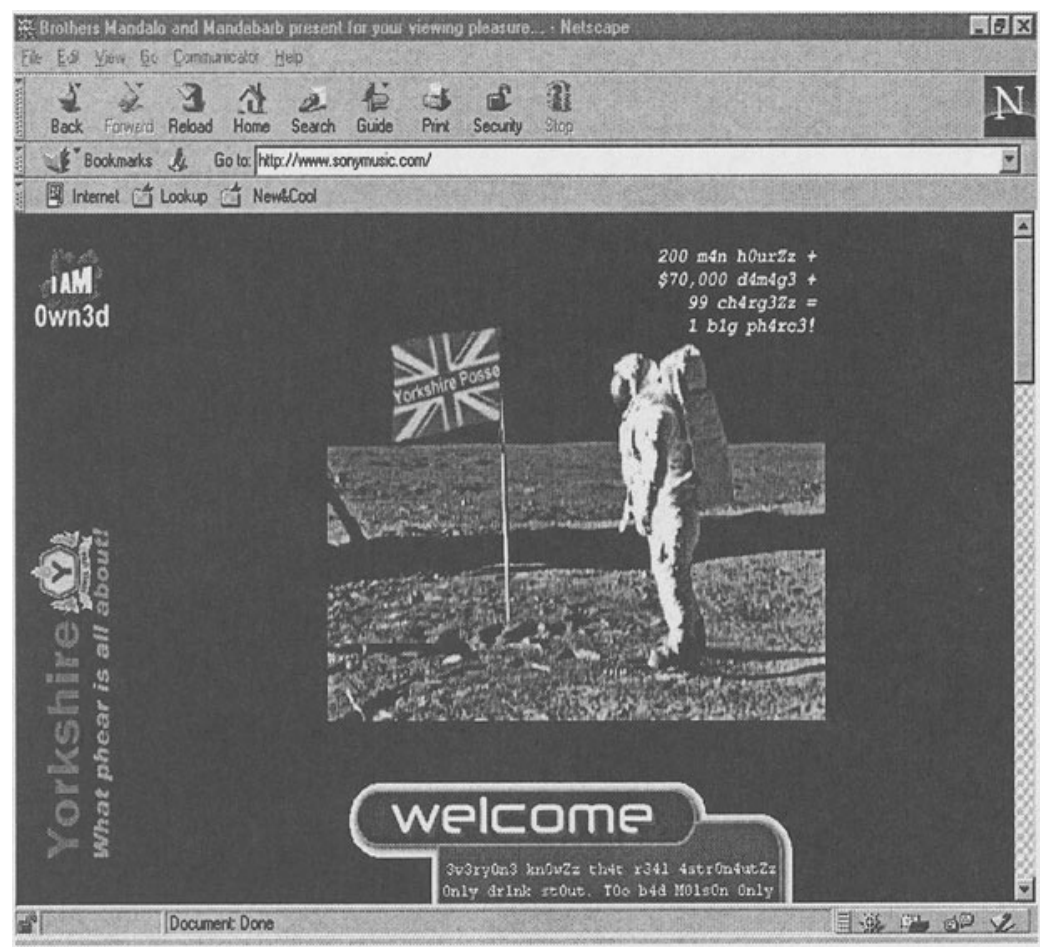

Figure 1: Successful hack of a large music company

\section{RESPONSE TO THE INFORMATION WARFARE PROBLEM}

The seriousness with which the issue of Information Warfare is taken can be illustrated by recent activities by national governments especially the USA. In the United States, for example, concern over IT related threats has led to the establishment of the National Infrastructure Protection Centre (NIPC). This is a US\$64 million facility, employing some 500 staff across the country, with representatives taken from existing agencies such as the 
Secret Service, the CIA, NASA, the National Security Agency, the Department of Defense and several others. The role of NIPC is to "detect, deter, assess, warn of, respond to, and investigate computer intrusions and unlawful acts" that threaten or target US critical infrastructures such as telecommunications, energy, banking and finance, water systems, government operations and emergency services [NIPC, 2000]. Without appropriate control, it is possible that measures could be introduced that are harmful to society in a different way. For example, the complete regulation or monitoring of our use of IT systems could lead to the emergence (some would say extension) of a "surveillance society" in which technology is used to erode individual rights and freedoms in the name of the wider public good [Davies, 1996]. It can already be seen that the activities of would be cyber attackers have started to restrict freedom for citizens. For example, despite some concessions, the United States continues to maintain a relatively restrictive policy on the use of cryptographic technologies. One of the stated reasons for control is to prevent unregulated use of strong encryption techniques by terrorist organisations [FBI, 1998].

\section{IS INFORMATION WARFARE A MYTH}

Many individuals describe Information Warfare as being a myth. The primary concern is Misinformation. In 1996 an official US government report [GAO, 1996] showed that the US Department of Defence experienced as many as 250,000 attacks in 1995 and of these $65 \%$ were successful. US officials within the US Air Force Information Warfare Center stated that this figure included everything from fumbled logins to simply fingering a system [Smith, 1998]. The figure cited was a guess according to other sources [Smith, 1998a], based on a much smaller number of recorded intrusions in 1995, the figure was an estimate and that US Department of Defence received reports of about 500 actual incidents in 1995. Because they believed that only 0.2 percent of all intrusions are reported, it multiplied its figure by 500 and this produced the figure 250,000 . Official FBI publications have also fallen victim to misinformation, an article about computer crime [Cater and Katz, 1996] described the impact of the "Clinton Virus", in reality the virus was a hoax and never existed. The Clinton Virus was a joke, as were all the other examples of viruses cited in the article. They had all been originally published in an April Fool's Day column of a computer magazine [Smith, 1998a]. But previous sections have shown that many countries take Information Warfare and risk to their NII very seriously. 


\section{CONCLUSION}

The paper has shown that countries are taking the risk of Information Warfare extremely seriously. The Australian government is now implementing a series of steps as defined by the Attorney General to try and protect Australia's NII in the future. The paper also shows that E-commerce is considered a weak aspect of the NII and may be the Achilles heal of the future. But is Information Warfare fact or fiction?

\section{REFERENCES}

Attorney-General's Department [1998], Protecting Australia's National Information Infrastructure, Report of the Interdepartmental Committee on Protection of the National Information Infrastructure, Attorney-General's Department, Canberra, Australia.

Cater, D and Katz, A. [1996] Computer Crime:An Emerging Challenge for Law Enforcement, FBI Law Enforcement Bulletin, December, USA.

Cobb.A. [1997], "Australia's Vulnerability to Information attack: Towards a National information Policy", Strategic and Defence Studies Centre working paper \#310, Australia National University, Australia.

Cobb, A. [1998]. Thinking about the Unthinkable: Australian Vulnerabilities to High Tech Risks, Australian Parliamentary Research Paper 18, Canberra, Australia.

Davies, S. [1996]. Big Brother - Britain's web of surveillance and the new technological order. Pan Book Ltd, London. ISBN 0-330-34931-7.

Denning, D. [1999]. Information Warfare and Security, Addison Wesley Longman Inc, USA, ISBN 0-201-433303-6.

DIST (Department of Industry, Science and Tourism). [1998]. Stats - Electronic Commerce in Australia, Commonwealth of Australia, Australia.

FBI. [1998]. Encryption: Impact on law Enforcement. Information Resources Division, Federal Bureau of Investigation, Virginia, US. 8 July 1998.

GAO [1996] GAO (General Accounting Office) Executive Report-B-266140, USA.

Howard, J. [1997]. PhD thesis An Analysis Of Security Incidents On The Internet, Carnegie Mellon University, USA.

Littman, J. [1997]. The Watchman - The Twisted Life and Crimes of Serial Hacker Kevin Poulsen. Little, Brown \& Company Limited, USA, ISBN 0-316-52857-9.

McIntosh, T. [1997]. 'Forum to tackle hack attacks'. The Australian, 30 September 1997, p. 33.

Mulschlegel, F. [1997]. Cyber Attacks: Detection and Prevention, InfoWarCon 97, pp B2 314, Brussels, Belgium.

NIPC. [2000]. Mission Statement, National Infrastructure Protection Centre. [On-line]. http://www.nipc.gov.

Schwartau, W. [1994]. Information Warfare: Chaos on the Electronic Superhighway. Thunder's Mouth Press, New York, USA, ISBN 1-56025-132-8.

Smith, G. [1998] An Info Warriors Wheels, Netly News Network, USA.

Smith, G. [1998a] An Electronic Pearl Harbor, Not Likely, Issues in Science and Technology, Fall 1998, The University of Texas at Dallas, USA. 